\title{
Hunter-prey correlation between migration routes of African buffaloes and early hominids: Evidence for the "Out of Africa" hypothesis
}

\author{
Vincent van Ginneken ${ }^{1,2 *}$, Aline van Meerveld ${ }^{1}$, Tim Wijgerde ${ }^{1}$, Elwin Verheij ${ }^{2}$, Evert de Vries ${ }^{1}$ and Jan van der Greef ${ }^{2,3}$ \\ ${ }^{1}$ Blue Green Technologies; 1: Blue Green Technologies; Runderweg 6; 8219 PK Lelystad; the Netherlands \\ ${ }^{2}$ TNO; P.O.Box 360; 3700 AJ Zeist; the Netherlands \\ ${ }^{3}$ Sino-Dutch Center for Preventive and Personalized Medicine; Leiden University; P.O.Box 9502; 2300 RA Leiden; the Netherlands
}

\begin{abstract}
Based on the similarity of migration routes of early bovines and early hominids (direct hunter-prey correlation) we postulate the hypothesis that early hunter hominids followed the herds of buffaloes and that the dispersal of early hominids pan-Africa is directly correlated to the historical migration of the African buffalo. This reasoning gives supportive evidence for the "Out of Africa" hypothesis. In addition, brain fattening ("brain steatosis") has previously been demonstrated after exposure of a juvenile mouse strain to a bovine lard High-Fat diet and starvation -as an evolutionary paradox- in whole brain using LCMS-techniques [1]. Here we postulate the hypotheses that accumulation of specific Triacylglycerols from bovine lard (large amounts of unsaturated C:50-1; C:50-2; C:52-2; C:52-3; C:54-3;C:54-4 and C:56-3 TGs) in early hominid brain could have contributed to encephalization in human evolution. Following this lipidomics based scientific approach [2] we gave supportive evidence for the "Out of Africa" hypothesis.
\end{abstract}

\section{Introduction}

In earlier studies in a High-Fat Diet obesity induced C57BL6 mouse model on $27.5 \%$ bovine lard we observed accumulation of specific Triacylglycerols (TGs) under conditions of starvation [3] but also after exposure to a High-Fat diet based on bovine lard [1], which gave evidence to the hypotheses that large amounts of TGs which where the 'prime movers' in brain evolution for skull expansion (encephalization) [4]. Thus we hypothesize that the unique lipid composition of bovine lard (large amounts of unsaturated TGs C:50-1; C:50-2; C:52-2; C:523; C54-3;C:54-4 and C56-3 TGs might play a role in mammalian encephalization ${ }^{1}$. We found a tight correlation with the HF-diet mouse brain composition with respect to these TGs to the HF-food diet: correlation coefficient $\mathrm{r}^{2}=0.760$ in comparison to control chow $\mathrm{r}^{2}=0.264$ [1]. Dietary quality has played a prominent role in theories of human evolution in general and the evolution of the human brain in particular (reviewed by [5]). Ideas of brain evolution centring on dietary quality until present (this study) not been confined to humans and human evolution [6]. Gibson [7] coined the "Extractive Foraging Hypothesis" to explain the relationship in primates. They argued that a relatively large brain correlates with omnivorous feeding in primates, which requires relatively complicated strategies for extracting high quality foodstuffs. The importance of a high quality diet, and meat eating in particular, has been a common theme [8]. Dietary quality has played a prominent role in theories of human evolution in general and the evolution of the human brain in particular. One of the most memorable of these theories is the 'Man the Hunter' $[9,10]$. This theory argued that increasing amounts of meat in the hominid diet lead to increasing levels of cooperation among the males in the hunt, which lead to brain expansion and the associated development of cognition, language and symbolic culture. This hypothesis was fueled by the realization that an increase in the apparent consumption of meat correlated with the increase in brain size seen in Homo habilis and Homo erectus. It was also supported by the recognition in the archaeological record of the basic elements of a hunter-gatherer life-style (home bases and food sharing) [11]. Although the rather simplistic reasoning underlying the 'Man the Hunter' hypothesis has lost favor in more recent years [12], the importance of a high quality diet, and meat eating in particular, has been a common theme $[8,13,14]$. But what was the source for meat? Luckily the evolution and dispersal and speciation of the early African bovines -the ancestors of the African savannah buffalo (Syncerus caffer) are by three important studies rather well documented: two mitochondrial DNA studies $[15,16]$ and one older paleontological study at the fossils of early African bovines [17]. African buffalo ( $\approx$ bovine lard) meat and brain were the basis for human Encephalization and the "Out of Africa" hypothesis [18], which supports our "African Buffalo Savannah" hypotheses. The single Out-of-Africa expansion theory - put simply postulates: that archaic Homo sapiens evolved to Anatomically Modern Humans (AMH) in Africa [19], between 200,000 and 150,000 years ago, and that members of one branch of AMH left Africa around 60,000 years ago and rapidly spread across Asia to Australia and across Europe

Correspondence to: Vincent van Ginneken, Blue Green Technologies; 1: Blue Green Technologies; Runderweg 6; 8219 PK Lelystad; the Netherlands, Email: vincent@bluegreentechnologies.nl or vvanginneken@hotmail.com

Key words: palaeoanthropology, bovine lards, overgrown brain, systems biology, human evolution, encephalization, skull expansion, Out of Africa (OOA) hypothesis, overgrown brain, African buffalo, (Syncerus caffer), early hominids, Homo erectus, Homo sapiens, migration routes, savannah, triacylglycerols.

Received: April 26, 2017; Accepted: May 12, 2017; Published: May 14, 2017 
replacing other branches of humans they encountered. Though there may have been many migrations out of Africa only the one at around 60,000 years ago - based on genetic dating - spread successfully. The "out of Africa" model (OOA-model) [20,21] proposed that modern $H$. sapiens speciated in Africa recently (that is, approximately 200,000 years ago) and the subsequent migration through Eurasia resulted in nearly complete replacement of other Homo species [20]. In contrast, the multiregional hypothesis proposed that Homo genus contained only a single interconnected population as it does today (not separate species), and that its evolution took place worldwide continuously over the last couple million years [22]. The hominin record from southern Asia for the early Late Pleistocene epoch is scarce. Well-dated and wellpreserved fossils older than $\sim 45,000$ years that can be unequivocally attributed to Homo sapiens are lacking.

In this respect mitochondrial DNA studies were extremely important which gave supportive evidence that as proposed by [23] a large and diverse human population has persisted in eastern Africa and that eastern Africa may have been an ancient source of dispersion of modern humans both within and outside of Africa.

Recently, [24] -as an evolutionary paradigm- described the archaeological findings of a collection of 47 anatomically modern human teeth from the Fuyan Cave in Daoxian, southern China was performed. Results can be interpreted that anatomically modern humans $(\mathrm{AMH})$ were in the region at least 80,000 years ago, and possibly as long as 120,000 years ago. That is $30,000-70,000$ years earlier than in the Levant and Europe. These people were much more modern-looking than hominins in northern and central China. The discovery adds to the complexity of the human story and shows that much remains to be discovered [24]. Despite these recent confounding paleoanthropological findings of [24] the recent African origin of modern humans, or the "out of Africa" theory (OOA), is the most widely accepted model of the geographic origin and early migration of anatomically modern humans. The concept was speculative before it was corroborated in the 1980s by a study of present-day mitochondrial DNA, combined with evidence based on physical anthropology of archaic specimens. Genetic studies and fossil evidence indicate that archaic humans evolved to anatomically modern humans solely in Africa between 200,000 and 60,000 years ago [18]. That members of one branch of Homo sapiens left Africa at some point between 125,000 and 60,000 years ago, and that over time these humans replaced other populations of the genus Homo such as Neanderthals and Homo erectus [19]. The savannas of the world currently are undergoing another phase of change as modern expansion of the human population impinges on the fauna especially the early hominid species In this regard, the human being adaptation began with Homo erectus who approximately 1.9 million years ago displayed strategies of life similar to Homo sapiens. The prominent change was the increased relative brain size that separated Homo erectus from australopithecines [25] (Figure 1) which is in conjunction to our initial hypothesis.

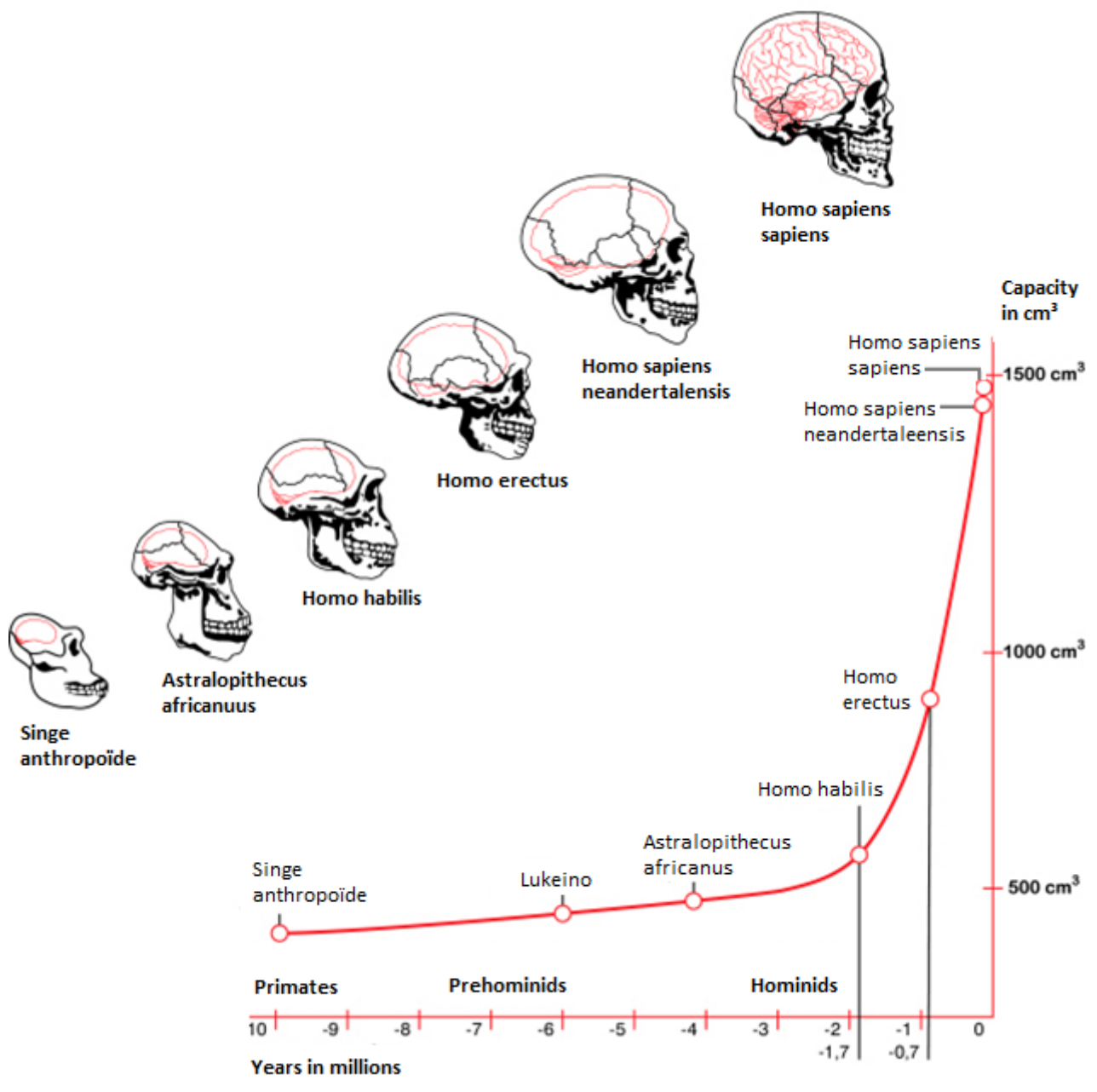

Figure 1. Human evolution based on skull endocasts of fossil archaic primates and early hominids. 


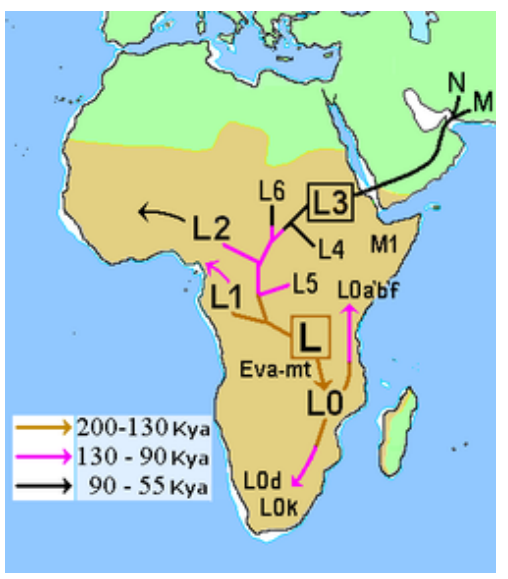

Figure 2. Map of early diversification of modern humans according to mitochondrial population genetics.

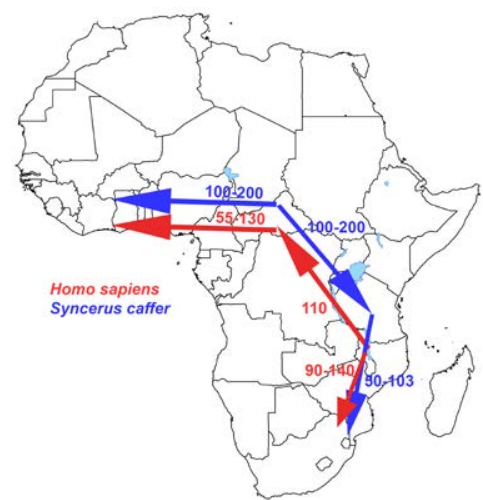

Figure 3. Our African Buffalo savannah hypothesis depicted.

Such early hunter gatherer societies were extremely dependent "by the bounty of the kill" [26], which was accompanied with such evolutionary traits as social interaction, language, tools and weapons development but also on the migration patterns of their preys.

We postulate the hypothesis that the early Bovinidae -with as subclass the early bovinae the ancestors of the several buffalo species which inhabited the savannah and migrated depending on the migration routes of the herds of buffalos -were the primary meat source. Meat and lard of bovines meet all demands for human consumption [1,27].

\section{Material and methods}

Figure 3 is developed based on:

1): Ancestors African Buffalo (Synercus caffer): The study of [16] identified based on a Bayesian analysis the most probable historical migration routes, with the Cape buffalo undertaking successive colonization events from Eastern toward Southern Africa

2): Early Homo sapiens http://www.Smitsonianmag.com/history/ the-great-human-migration

\section{1}

\section{Haplogroups: L3, E, B Across Africa (Figure 2).}

This lineage spread from east-central Africa to northwestern Africa at a time when the climate and

landscape became more hospitable. They settled from the central-
West African coast to North

Africa. In the north, people from this line are now part of populations such as the Berber peoples,

who are traditionally livestock herders. Toward west-central Africa, this line has descendants

among traditional farming groups (Source: Smithsonian Institute online available).

B:Haplogroups L,B,E: Central Africa to West Africa (Figure 2).

Early humans moved from Central Africa to West Africa in this migration. Their descendants include the Bantu-speaking peoples. The Bantu had an advanced farming culture, and were the first people in sub-Saharan Africa to work iron. Later expansions to the east and south introduced agriculture across Africa and spread the Bantu languages throughout the continent.

\section{Haplogroups: L0, E, A: Across Africa (Figure 2).}

Humans traveling this route spread from east-central Africa to southern Africa. Their descendants include central African Pygmies and the Khoisan-the famous Bushmen of the Kalahari. The Pygmies live in the rain forests as hunter-gatherers. The Khoisan people live in the harsh lands of southern Africa. Some of them are hunter-gatherers; others herd livestock.

\section{Haplogroups: L4, L5, L6, E, DE, F: Out of Africa to the Fertile Crescent}

This route took humans on an out-of-Africa migration into the lands that would become the Fertile Crescent. Though at first they were nomads, they eventually became some of the earliest farmers. The creation and growth of agriculture led to cultural changes that have been linked to the development of art, textiles, religion, and other hallmarks of human civilization.

\section{Haplogroups: E, M, N, Q, C, D, CT: Out of Africa to Asia and Australia}

Early humans on this path traveled out of Africa and along the coastline of Asia toward Indonesia. Many of them continued until they reached Australia-they founded the Aboriginal population there.

All haplotypes involved in a global dispersal are mentioned for completeness under $\mathrm{M} \& \mathrm{M}$ but for our African model -supporting the Out Of Africa (OOA) hypothesis- solely section A, B, C with mentioned haplotypes are important. The African root was the source of four lineages specific for sub-Saharan Africa: L0, L1, L2 and L3 in our model (130,000-200,000 YBP) (Source Wikipedia \& modified [28]). Our laboratory observations at an obese mouse model with overgrown brain due to TGs from bovine lard [1] can hopefully contribute in an understanding of African history of early hominids and their bovine preys which we hope to achieve by this hypothesis brief communication.

As mitochondrial DNA (mtDNA) is uniparentally inherited, it undergoes negligible recombination at the population level, and mutations acquired over time have subdivided the human population into several discrete haplogroups. The major haplogroups arose 40,000-150,000 years before present (YBP) and have defined different human populations as they migrated out of Africa and populated the globe. The African root was the source of four lineages specific for subSaharan Africa: L0, L1, L2 and L3 in our model (130,000-200,000 YBP) 
(Source Wikipedia \& modified [28]).

\section{Results and discussion}

Our major outcomes of the "African Savannah Buffalo hypothesis" are depicted in Figure 3 which gives the similarity of dispersal/ migration routes of early bovines and early hominids (direct hunterprey correlation/association). As earlier mentioned in the Introduction this map (Figure 3) is based on the observation of a C57bl6 obese mouse model with an overgrown brain due to accumulation of Triacylglycerols (TGs) from bovine lard in the brain from the feed (High-fat diet) during their juvenile growth phase [1]. To our awareness never before brain expansion due to nutritional intervention has been observed in a mouse model related to TGs accumulation due to a High-fat diet based on bovine lard. We expanded this observation towards the research area of paleanthrophology and encephalization of early hominids and via this route we came to the "Out Of Africa" (OOA) hypothesis. We are aware we are no specialist and this research area is totally new to us. However, our observation could be valuable because just like modern mitochondrial DNA techniques gave a major "Leap Forward" in the research area of paleoanthrophology, this could also be the case using a Systems Biology, Lipidomics based approach using LCMS techniques in mouse models [1] or post mortem human brains (in preparation), because our evolution is -to our awareness- literally engraved in our human brain. To give some structuring to our perception, African buffalo meat has -we hypothesize- some specific TGs composition which makes it easy to pass the Blood-brain barrier (BBB), in this way triggering brain growth.

Modern human expansion process out of Africa has important implications for understanding the genetic and phenotypic structure of extant populations. Most of the diverse bovid species occurred in Africa. The maximum concentration was in the savannas of eastern Africa. This also seems to be the period in which Cape buffalo evolved as a separate subspecies, according to the net sequence divergence with the other subspecies. These two observations are in agreement with the hypothesis of a rapid evolution of Cape buffalo based on fossil data [17]. Additionally, there appears to have been a population expansion from eastern to southern Africa, which may be related to vegetation changes. So sufficient meat and lard was available to transform the brains of these early hominids by the earlier described "brain steatosis" mechanism [1]. The African buffalo (Syncerus caffer) exhibits extreme morphological variability. Recent molecular analysis using a comprehensive set of mitochondrial $D$-loop sequences from across the entire range of the species. All analyses converged on the existence of two distinct lineages, corresponding to a group encompassing West and Central African populations and a group encompassing East and Southern African populations. The two lineages of the African buffalo most likely expanded and diverged in the late to middle Pleistocene with strong indications for a population expansion in both lineages which diverged between 145000 to 449000 years ago [16]. In arguing so, the study of [16] identified based on a Bayesian analysis the most probable historical migration routes, with the Cape buffalo undertaking successive colonization events from Eastern toward Southern Africa (Figure 1). Furthermore their analyses indicate that, in the West-Central African lineage, the forest eco-phenotype may be a derived form of the savanna eco-phenotype and not vice versa, as has previously been proposed [16]. This recent study supports earlier paleontological findings at the bovid fossils from Elandsfontein, south-western Cape Province, south-Africa, which compromises 7257 individually numbered specimens from 18 buffalo species. Taxonomic comparisons with Olduvai Gorge and other African sites and the high percentage of extinct forms imply that the bones accumulated in the earlier part of the Middle Quaternary, probably sometime between 700,000 and 400,000 years ago [17]. Also based on mitochondrial and Y-chromosomal loci at these ancestors of the modern African buffalo it was concluded it had a Pleistocene origin and population expansion [15]. In conjunction with the paleontological studies of [17] at the coast of South Africa at fossils of ancestors of the present modern African buffalo in the same area at South African Cape-sites. Similarity of early hominids to these migration routes of also these early African buffalo species supports the "Out-Of-Africa" theory. We hope that our results and initial evolutionary hypothesis termed "The African Savannah Buffalo" hypothesis will stimulate further work on this important topic.

Similarity of migration routes of early hominids with these of the African buffalo (Syncerus caffer) -hunter-prey linkage- most likely expanded and diverged in the late to middle Pleistocene from an ancestral population located around the current-day Central African Republic with the Cape buffalo undertaking successive colonization events from Eastern toward Western and Southern Africa.

\section{Conflict of interest}

None

\section{References}

1. van Ginneken V, de Vries E, Verheij E, van der Greef J (2017) "Brain steatosis" in an obese mouse model during cycles of Famine and Feast: the underestimated role of fat (WAT) in brain volume formation. Integr Mol Med 4: 1-6.

2. van der Greef J (2011) Perspective: All systems go. Nature 480: S87. [Crossref]

3. van Ginneken V (2007) Metabolomics (liver and blood profiling) in a mouse model in response to fasting: a study at hepatic steatosis. Biochim Biophys Acta 1771: 12631270.

4. Williams MF (2002) Primate encephalization and intelligence. Med Hypotheses 58 284-290. [Crossref]

5. Aiello LC (1997) Brains and guts in human evolution: The Expensive Tissue Hypothesis. Current Anthropol 36: 199-221.

6. Parker ST, Gibson KR (1979) A developmental model for the evolution of language and intelligence in early hominids. Behav Brain Sci 2: 367-407.

7. Gibson KR (1986) Cognition brain size and the extraction of embedded food resources In: Primate Ontogeny Cognition and Social Behavior (Else JG \& Lee PC eds) Cambridge University Press Cambridge pp 93-105.

8. Leonard WR, Robertson ML (1992) Nutritional requirements and human evolution: A bioenergetics model. Am J Hum Biol 4: 179-195.

9. Ardrey R (1961) African Genesis Dell New York.

10. Washburn SL, Lancaster CS (1968) The evolution of hunting In: Man the Hunter (Lee RB \& DeVore I eds) Aldine New York pp 293-303.

11. Isaac GL (1971) The diet of early man: aspects of archaeological evidence from lower and middle Pleistocene sites in Africa. World Archaeol 21: 278-299.

12. Tanner NM (1981) On Becoming Human. Cambridge University Press, Cambridge.

13. Foley RA, Lee PC (1991) Ecology and energetics of encephalization in hominid evolution. Philos Trans R Soc Lond B 334: 223-232.

14. Leonard WR, Robertson ML (1994) Evolutionary perspectives on human nutrition: The influence of brain and body size on diet and metabolism. Am J Hum Biol 6: 77-88

15. van Hooft WF, Groen F, Prins HHT (2002) Phylogeography of the African buffalo based on mitochondrial and Y-chromosomal loci: Pleistocene origin and population expansion of the Cape buffalo subspecies. Mol Ecol 11: 267-279.

16. Smitz N, Berthouly C, Cornélis D, Heller R, Van Hooft P, et al. (2013) Pan-African Genetic Structure in the African Buffalo (Synerus caffer): Investigating Intraspecific Divergence. PLoS One 8: e56235.

17. Klein RG, Cruz-Uribe K (1991) The bovids from Elandsfontein South Africa and their implications for the age palaeo-environment and origins of the site. The African Archaeological Review 9: 21-79. 
18. Mellars P (2006) A new radiocarbon revolution and the dispersal of modern humans in Eurasia. Nature 439: 931-935. [Crossref]

19. Meredith M (2011) Born in Africa: The Quest for the Origins of Human Life New York: Public Affairs ISBN 1-58648-663-2.

20. Stringer CB, Andrews P (1988) Genetic and fossil evidence for the origin of modern humans. Science 239: 1263-1268. [Crossref]

21. Stringer C (2003) Human evolution: Out of Ethiopia. Nature 423: 692-693, 695 [Crossref]

22. Wolpoff MH, Spuhler JN, Smith FH, RadovciÄ J, Pope G, et al. (1988) Modern human origins. Science 241: 772-774. [Crossref]

23. Gonder MK, Mortensen HM, Reed FA, de Sousa A, Tishkoff SA (2007) Whole-mtDNA genome sequence analysis of ancient African lineages. Mol Biol Evol 24: 757-768.
24. Liu W, Martinón-Torres M, Cai YJ, Xing S, Tong HW, et al. (2015) The earliest unequivocally modern humans in southern China. Nature 526: 696-699. [Crossref]

25. Wood B, Collard M (1999) The human genus. Science 284: 65-71. [Crossref]

26. van Ginneken V (2008) Liver fattening during famine and feast an evolutionary paradox. Medical Hypotheses 70: 914-928.

27. Doyle E (2004) Saturated Fat and Beef Fat as Related to Human Health: A Review of the Scientific Literature FRI Briefings Food Research Institute University of Winconsin Madison WI 53706; 28 pp.

28. Gonder MK, Mortensen HM, Reed FA, de Sousa A, Tishkoff SA (2007) Whole-mtDNA genome sequence analysis of ancient African lineages. Mol Biol Evol 24: 757-768. [Crossref]

Copyright: $(2017$ van Ginneken V. This is an open-access article distributed under the terms of the Creative Commons Attribution License, which permits unrestricted use, distribution, and reproduction in any medium, provided the original author and source are credited. 